\title{
Estimation of the parameter of satisfaction with services in tourism: content analysis of online customer reviews
}

\author{
Leonid Kapilevich $^{1,2, a}$, Yulia Karvounis ${ }^{2}$, and Diana Zagulova ${ }^{3}$ \\ ${ }^{1}$ Tomsk Polytechnic University, 634050 Lenin Avenue, 30, Tomsk, Russia \\ ${ }^{2}$ Tomsk State University, 634050 Lenin Avenue, 36, Tomsk, Russia \\ ${ }^{3}$ Baltic International Academy, LV-1003 Lomonosova str., 4, Riga, Latvia
}

\begin{abstract}
To increase the competitiveness the hotels have to satisfy their guests' requirements, anticipate their wishes and offer new services; this is quite problematic for the hotel business. The paper considers the opportunities of employing online guest reviews to reveal the hotel ratings and attributes, significant for guests. The implementation of this research method is specified by the quality of information obtained via the internet; it is published on a voluntary basis, statements are initiated by users; moreover, consumers estimate the services and offers, having certain emotional importance for them; it allows segmenting the factors according to the level of their emotional significance. This segmentation is of utmost importance since the principal aim of the researches devoted to the assessment of the level of consumers' satisfaction is to reveal the indicators of company activities from the position of customers' priorities and emotional evaluations. The content analysis discovers the indicators, significant for the beach hotels customers. 90 hotels were grouped according to 16 categories. The results display that the guests responses can be used for investigating the importance of hotel attributes and determining the peculiarities of various hotel customers groups. The obtained results can be used for service package improvement and for hotel description in advertisement and reservation systems.
\end{abstract}

\section{Introduction}

There is a great deal of pressure on enterprises of the hospitality industry from market forces, which demand competitive growth. The main competitive advantage in the hotel business is to create a combination of goods and services which satisfy the desires, meet the requirements and answer or heighten client's expectations.

In order to work effectively hoteliers need not only to offer commercially viable services but also to "speak the customers' language" in marketing, using controlled factors of attraction. In other words, to include information about the hotel which is significant for a customer. In addition, it is preferable to use target texts, where the interests of a particular customer are taken into consideration.

The hoteliers who have a clear understanding of consumer's needs have definite competitive advantages. Understanding of customers while making decisions is necessary in order to predict their future intentions, and this is vitally important for success in the hotel business [1]. However, different types of face-to-face and remote interviews (group and individual, formalized and nonformalized, non-structured and structured, etc.) as well as focus groups, questionnaires, online surveys and others are used in marketing research in order to reveal factors of attractiveness [2]. The relevance of such research may decrease due to some reasons. Firstly, the consumer is not the initiator of this research and, secondly, the characteristics included in a questionnaire are selected by the researcher and, in this case, some of them which are significant for a customer may be neglected.

In the 21 st century there appeared another possibility to reveal customers' needs and to research their evaluative judgments, viz. the use of the World Wide Web environment. There are some special websites where travellers share their impressions, evaluate tourism destinations and give recommendations. A number of reservation systems use customers' comments in order to form top lists of hotels. In recent years publications started to appear; social networks are used in order to evaluate the satisfaction of hotel customers and to define the significance of different services and sources of satisfaction, as well as to research the target segments and behaviour of consumers of tourism services.

This research is aimed at finding solutions to some issues:

\footnotetext{
${ }^{\mathrm{a}}$ Corresponding author: kapil@yandex.ru
} 
1. Which characteristics of hotels do guests use in their comments?

2. What are the relative frequencies of use of hotel characteristics in comments?

3. Is there any difference between the top lists of hotels in comments and in research papers, which investigate the significance of different characteristics by means of other methods?

4. Can the information received from comments on hotels help to make the description of hotels better in reservation systems and other publications?

5.Is it possible to use comments published by customers in reservation systems in order to reveal the factors significant for hotel guests?

The answers to these questions will help to understand what kind of information to present and how to do it on websites of hotels and in other marketing publications as well.

\section{Materials and methods}

While planning trips, comments are generally searched in such online communities as TripAdvisor, Virtual Tourist, Lonely Planet and others, on the websites of tourist guides, travel agencies, etc. [3]. That is why, in order to reveal the characteristics of hotels which are significant for customers, publicly available comments, which are posted on the most popular tourist websites in Russia, were used. They are booking.com, tripadvisor.com, curtour.ru, mahnem.ru, otzyv.ru, rgbtour.ru, tophotels.ru, tourprom.ru, hrs.com, 100dorog.ru, turizm.ru, mirputeshestvii.ru, agoda.com, traveltipz.ru. The total of 797 randomly chosen comments on one to five star beachside hotels were analysed. Sixty comments taken from each website except for curtour.ru were researched; 17 comments from curtour.ru were studied.

The total number of hotels researched using random choice was: one star $-4(0.5 \%)$, two stars $-16(2.01 \%)$, three stars $-169(21.20 \%)$, four stars -331 (41.53\%), five stars $-260(32.62 \%)$ and 17 hotels $(2.13 \%)$ without indication of the number of stars, taken from website curtour.ru. Content analysis was used in order to analyse comments. The method of content analysis characterises the meaning of message content on a regular basis and by means of quality [4]. At the moment different automated methods and combinations of them are used in order to analyse texts and to obtain information. For example, Text Mining (TM), content-based SNA [5]. However, there is an opinion that current disparity between machine processing and human capacities does not allow us to do without manual processing of texts [6]. In this paper, after the words had been extracted using some machine processing methods, selection and classification were made without a computer. During the process of content analysis all the characteristics which described hotels were recorded. In addition, the characteristics were considered significant both for customers with positive and negative comments.

Fractions of characteristics were identified in the total of comments in order to rate them. Fractions were calculated as the proportion of comments' frequency, where the given characteristic was mentioned, to the total of comments in percentage. The percentage of comments was identified, where the characteristics related to the given category were used once or more often, in order to calculate the fraction of the category. The value of difference of the fractions of the category was first identified according to a $95 \%$ confidence interval. A 95\% confidence interval was used because it not only allows identification of the spread of data, but it also can be used instead of usual criteria in order to evaluate the statistical significance of differences [7]. The value of difference of the fractions was checked using the difference between two proportions in Statistica 8.0. for those categories whose $95 \%$ confidence interval did not intercross.

\section{Results and discussion}

In order to attract a customer to a hotel it is important not only that the hotel must have everything for their comfort, but it is also necessary to tell them about it in a proper way when they are choosing a hotel. A tourist will choose the hotel whose facilities are presented in a better way. That is why in order to promote a hotel, first of all, it is necessary to know which characteristics are considered significant by customers. Customers' interests can be researched according to the frequency of use of topics or words in texts, which they write on the Internet. Repetition is one of the easiest ways to identify the topics which are significant for the authors. Frequently used words (topics) are more important for customers [8]. The analysis of those very travellers' Internet texts is important for another reason too - competition for clients is mainly concentrated on the Internet [9].

The characteristics of hotels, which are significant for customers, are researched in this paper. That is why, in this case, it is not important how many comments could have been written by interested parties. Nevertheless, the issue of possible false comments is undoubtedly interesting. This paper follows some ideas. First of all, reservation systems are interested in avoiding paid comments and protect themselves from this. Secondly, the results of the work by Gretzel [3] showed an absence of proof for significant influence of false comments and he claims that it is impossible to change a hotel's rating dramatically by using shill reviews. That is why Gretzel [3] considers concerns about a widespread use of false comments, at least on TripAdvisor, to be groundless.

The results of content analysis of hotel guests' comments are expressed in the following. A total of 90 characteristics were identified while conducting the content analysis, some of which were merged in order to increase their significance for statistical analysis. Finally, 69 characteristics were obtained. All the identified characteristics of hotels were grouped together in 16 categories on the basis of functional relationship: Services, Hotel Territory, Finances, Location, Aesthetic Characteristics, Service Quality, Communications, 
Safety, Food, Conveniences, Entertainments, and Special Facilities.

The obtained data analysis allowed us to define which characteristics of hotels are the most and the least frequently used by those who comment on hotels. A preliminary conclusion about the difference in frequencies of mention of categories in comments on hotels can be drawn according to the crossings of values of $95 \%$ confidence intervals. If the confidence intervals cross, frequencies of mention of categories in comments are improper to consider different [7].

The characteristics referring to the category "Service Quality" were most frequently mentioned in comments, 71.1\% (567). "Room Conditions", 64.7\% (516) and "Personnel", 61.1\% (487) are the second most frequently mentioned in comments. This result is highly expected because, first of all, hotel guests pay for the quality of the room and hotel services which are provided by hotel personnel. Apparently, this is why those who comment consider these categories more important to express in their comment.

"Cuisine", 49.6\% (395), is in third place. This category involved such characteristics as "Flavour Profile", "Abundance and Freshness of Food", "Availability of National Cuisine" and "Availability of Separate Menu". There is no telling that the frequency of use of such characteristics as "Location", 44.0\% (351) and "Aesthetic Characteristics", 44.0\% (351) is of great difference in comparison with "Cuisine". The rest of the categories were mentioned in approximately $37-22 \%$ of comments. It was unexpected that the words referring to the category "Safety", 9.5\%, were the least frequent in comments.

The research of the top list of characteristics, which are important while choosing a hotel, is necessary both for management and marketing. In the sources the list of characteristics which are significant while choosing a hotel consists of: cleanness, convenience, room facilities and its state, location, quickness, politeness and service quality, price, value for money, interpersonal relationships and hotel area safety [1]. In our research the most frequently used characteristics in comments were "Service Quality" - 71.14\% (567), "Room Conditions" - 62.11\% (495), "Personnel" - 61.10\% (487), and "Cuisine" - 49.56\% (395).

"Safety" was mentioned as one of the most important choice factors of a hotel in many works [10, 11]. However, the fact which attracts attention in this research is that the words which determine various sides of "Safety" are too rarely used in the comments. Thus, the words related to safety in location were found only in 7 comments $(0.88 \%)$ and those related to safety in the streets in 8 comments $(1.00 \%)$. It should be noticed that while analysing the comments on hotels there were not any words related to safety in Akehurst [11].

In some research the hotel location is defined as the key characteristic while choosing leisure areas [1]. The price of a hotel may be at least $13-17 \%$ higher if it is located near the beach [12]. The category "Location" is mentioned in this research only in $44.04 \%$ (351), and, on the whole, in terms of its location not far from tourist attractions in $38.90 \%$ (310).
The words describing taste, $40.40 \%$ (322), and aesthetic, $44.04 \%$ (351), characteristics are quite often found in the researched comments. However, they are not indicated as significant ones and are practically unmentioned in works related to the research of significant characteristics of choice of hotels.

The price-quality relationship is mentioned in the comments not so often, only in $25.22 \%$ (201) of comments, which also contradicts the data in the literature. Discounts and promotions of hotels are far less often described in the comments, only in $3.64 \%$ (29). However, if the customers were asked to evaluate the significance of these characteristics while choosing a hotel, they would surely have a high rating position.

The fact that the rating of characteristics of hotels in opinion polls among guests may neither coincide with their factual use nor with true value for a comfortable stay at a hotel is noticed in some works. For example, despite the fact that a swimming pool is one of the services which is expected in full-service hotels by $83-$ $92 \%$ of guests, only $29 \%$ of them actually use it. In the research by Ariffin and Maghzi [13] the characteristic "Comfort" was evaluated as the least significant in comparison with more ethical ones, such as "Personalized service", "Warm Welcoming", "Special Relationship" and "Straight from the Heart". Although customers considered "Comfort" the least significant, it is of crucial importance to feel comfortable in order to make one's stay in a hotel memorable.

The use of online reservation of hotels tends to grow year by year. More and more hotels use this option on their websites, in reservation systems and in public tourist services. When this happens, both online reservation technologies and customers are constantly changing. That is why the issues of monitoring of hotel guests' behaviour in the frame of Internet use remain urgent. Numerous research shows that while choosing a hotel, customers are geared to the comments of hotel guests [3, 14]. On the one hand, it is claimed that customers trust comments more [13, 15], but, on the other hand, comments may contain that necessary information which neither reservation systems nor hotel website contain. That is why we compared the characteristics which are used in reservation systems with those taken from customers' comments.

The words connected with cuisine and taste characteristics, $49.56 \%$ (395), are used in a significant number of comments. At the same time, the kinds of meal which are mentioned in hotel descriptions (BB, $\mathrm{HB}, \mathrm{FB}, \mathrm{AI}, \mathrm{UAI})$ are found in less than $13 \%$ of comments. Many hotels pay much attention to the dishes they offer, the food and the atmosphere in a restaurant. However, there is no information about these particularities which are important for customers in hotel descriptions. For example, on website booking.com there is a filter "Gourmet", but there is no information about "Special Diet", "National and Other Types of Cuisine", which is attractive for tourists at the moment [17].

There are more and more tourists who are interested in the aesthetic qualities of the interior and landscape around hotels. "Aesthetic Characteristics" were mentioned in $44.04 \%$ (351) of comments in our research. 
One can choose a hotel with "View", "Nature/wildlife" and "Design" at booking.com. As a rule, such hotels publish appropriate illustrations. However, there is appropriate information about rather few of the hotels which are identified as those with a fine view and interior.

For example, booking.com, the most popular reservation system, gives hoteliers an opportunity to describe in detail everything which is remarkable for each hotel according to the following categories: "Internet", "Outdoors", "Media \& Technology", "Food \& Drink", "Parking", "Services", "General", "Languages Spoken" and some others. However, by no means all the hotels fully realize the given opportunity. Very little attention is paid so far to such significant characteristics for customers as: "Aesthetic Characteristics", "Peculiarities of Cuisine", "Location of Tourist Attractions and Ability to Visit Them", "Languages Spoken", "Quality of Beach and Sea", "Entertainment Programs" and others. It is only booking.com which expresses customers' interests, which were identified in comments, better than the other reservation systems, but still not to a full extent. In fact, these characteristics are necessary for a hedonic pricing method, which is more profitable for hoteliers.

\section{Conclusion}

The characteristics of beachside hotels which are significant for customers were identified. The absence, a low quality or presence of these characteristics makes sense for the emotional resonance of a leisure area. The analysis of hotel guests' comments showed that similar text messages may be used, with some restrictions, both in hotel management and marketing. The characteristics which are significant for beachside hotels guests were identified using content analysis. That is why the obtained results may be used not only to make the service package better but also to describe hotels both in advertising and in reservation systems.

The main advantage of the information obtained from web-based media is that service receivers make comments voluntarily. Unlike that research, which is carried out by an institution, such evaluations may be more valid because they are initiated by the customers themselves. Despite this, in their comments consumers evaluate those services and offers which are emotionally significant. This may allow characteristics to be segmented according to the level of emotional significance. The latter makes great sense because the overarching aim of research which evaluates consumers' satisfaction is to identify the performance level of a company from the point of view of consumers' priorities and their emotional evaluation. This, in its turn, will let hoteliers use a hedonic pricing method.

Consumers must receive what they want, when they want it and how they want it. That is why companies have to strive not only to satisfy consumer expectations but also to make customers admire their giving them even more than they can expect. In the 1970s, Noriaki Kano, a Japanese academic and consultant, suggested a model where consumers' satisfaction is identified by five emotional responses to products/services, ranked from aversion to admiration. What is more, Kano criticised the opinion that it is possible to retain consumers' loyalty by means of reacting to their complaints and enlarging the most popular characteristics of this product. That is why the most difficult and important task for the efficiency of the hospitality business is to develop new offers and services which will improve the attractiveness of a hotel and loyalty of travellers. The recommendations on desired services, which can be used in order to develop packages, may be rarely obtained in compulsive opinion polls. Apparently, this problem can be solved more effectively using content analysis of web-based media on various websites. However, according to the research undertaken, it is not enough to address only the comments which are made by hotel guests. In the analysed comments there was no information which could be used in order to develop new offers. A larger area containing similar information is situated in weblogs, social networks, forums and specialized websites for travellers.

Not only those characteristics which are often mentioned are important for hotel marketing. The characteristics which are rarely mentioned are nonetheless important. A marketing policy and offers may be formulated using the dynamics of frequencies of mention of various words, their emergence and disappearance. Rare words may appear due to some reasons. First of all, apparently, those characteristics which are considered basic indifferent are rarely used in comments. The characteristics may be those which were used by consumer to filter hotels in reservation systems. Probably, this is why such categories as "Beach and Swimming Pool", "Finances", "Room Facilities", "Communications", "Services", "Kinds of Food and Drinks", "Entertainments", "Hotel Territory" are mentioned in more than $37 \%$ of comments.

The obtained results may be used in order to make the description of hotels better, which will ease the consumer's choice and may reduce anxiety in regard to an acquired service. Despite this, it should be mentioned that information which is accurately structured and classified may become useful in the future when searches using artificial intelligence are available.

\section{References}

1. P. Z. Baruca, Ž. Civre, Academica TuristicaTourism and Innovation Journal, 5(1) (2012)

2. N. Hill, B. Selphie, G. Roche, Measuring customer satisfaction ISO 9000: 2000. (Moscow: Publishing House "Technology", 2004)

3. U. Gretzel, K. H. Yoo, M. Purifoy, Online travel review study: Role and impact of online travel reviews (2008)

4. J. W. Strijbos, R. L. Martens, F. J. Prins, W. M. Computers \& Education, 46(1) (2006)

5. A. Bohn, I. Feinerer, K. Hornik, P. Mair, The R Journal, 3(1) (2011) 
6. M. Del-Fresno-García, Infosociabilidad: monitorización e investigación en la web 2.0 para la toma de decisiones, 20(5) (2011)

7. Glantz, S. A. Primer of biostatistics. (McGraw-Hill Medical, 2005)

8. G. W. Ryan, H. R. Bernard, Techniques to identify themes. Field methods, 15(1) (2003)

9. J. J. Shuai, W. W. Wu, Expert systems with applications, 38(7) (2011)

10. M. Ananth, F. J. DeMicco, P. J. Moreo, R. M. Howey, The Cornell Hotel and Restaurant Administration Quarterly, 33(4) (1992)

11. G. Akehurst, User generated content: the use of blogs for tourism organisations and tourism consumers, 3(1) (2009)

12. R. Rigall-I-Torrent, M. Fluvià, Tourism Management, 32(2) (2011)

13. A.A.M. Ariffin, A. A. Maghzi, International Journal of Hospitality Management 31 (2012)

14. H. J. Schau, M. C. Gilly, Journal of consumer research, 30(3) (2003)

15. Pan, B., MacLaurin T., Crotts J. Travel blogs and their implications for destination marketing. J Travel Res 46(1), (2007)

16. A. Atkinson, Answering the Eternal Question What Does the Customer Want, 29(2), 12-14 (1988)

17. I. Liu, W. C. Norman, L. A. Pennington-Gray, Flash of Culinary Tourism, 13(1) (2013) 